\title{
Productivity of Osprey, Pandion haliaetus, Nesting on Natural and Artificial Structures in the Kawartha Lakes, Ontario, 1991-2001
}

\author{
Pamela A. Martin ${ }^{1}$, Shane R. de Solla ${ }^{1}$, Peter J. Ewins ${ }^{2}$, and Michael E. Barker ${ }^{3}$ \\ ${ }^{1}$ Canadian Wildlife Service, Environment Canada, Box 5050, 867 Lakeshore Road, Burlington, Ontario L7R 4A6 Canada \\ ${ }^{2}$ World Wildlife Fund, 245 Eglington Avenue East, Toronto, Ontario M4P 3J1 Canada \\ ${ }^{3}$ Wetland Habitat Fund, 1289 Algonquin Blvd., Peterborough, Ontario K9H 6N1 Canada
}

\begin{abstract}
Martin, Pamela A., Shane E. de Solla, Peter J. Ewins, Michael L. Barker. 2005. Productivity of Osprey, Pandion haliaetus, nesting on natural and artifical structures in the Kawartha Lakes, Ontario, 1991-2001. Canadian Field-Naturalist 119(1): 58-63.
\end{abstract}

Ospreys (Pandion haliaetus) declined throughout the Great Lakes basin during the 1950s to 1970s due to usage of organochlorine pesticides. Following the banning of DDT in 1972, artificial elevated nest structures were erected in the Kawartha Lakes region of south-central Ontario to aid in their recovery. As the population grew, large stumps of flooded trees, $<1 \mathrm{~m}$ above the surface of the water became important nesting sites, despite their propensity to flood in turbulent weather conditions. We compared the productivity of Ospreys among nest substrates and longevity of the nests in this area from 1991 to 2001. Of 260 individual nesting attempts made over the 11 years, 57\% used man-made structures, primarily either quadrupod nesting platforms or utility poles. Of nests on natural substrates, stump nests accounted for $37 \%$ of total nesting attempts; elevated tree nests were relatively uncommon (6\%). Productivity of stump nests was significantly greater than that of artificial or tree nests (1.48 versus 1.16 and 0.73 chicks produced per occupied nest, respectively). Nevertheless, survivorship of stump nests was less than that of platform nests after 3 years of age, as high water levels, storms or winter ice activity destroyed some of these low nests between breeding seasons. Ospreys were able to attain greater productivity in these stump nests than on man-made nesting substrates.

Key Words: Osprey, Pandion haliaetus, nest success, productivity, nest platforms, Ontario.

Osprey (Pandion haliaetus) populations in the Canadian Great Lakes basin underwent a severe decline in response to organochlorine pesticides between 1950 and 1972; however, numbers had already been depleted earlier in the century due to habitat loss through deforestation and the onset of intensive agriculture and urbanization (Ewins et al., 1995). As populations gradually recovered in the 1970s following the ban on the use of DDT, Ospreys began using a wide variety of man-made structures, such as utility poles, television antennae and navigation markers, as support for their bulky stick nests (Ewins 1996). In addition, Ospreys readily utilize custom made nesting platforms, typically located on quadrupods or tripods, $3-5 \mathrm{~m}$ in height, embedded in the sediment in the littoral zones of lakes, or mounted on disused utility poles on rocky islands (Ewins 1996). By the mid 1990s, 36\% of occupied Osprey nests in the Great Lakes basin were on artificial structures.

In 1978, the Ontario Ministry of Natural Resources began monitoring a recovering Osprey population in the Kawartha Lakes region of south-central Ontario. During the course of the study, artificial nesting platforms were erected for their use. In 1991, the Canadian Wildlife Service initiated a study to determine if Ospreys breeding on the Great Lakes were continuing to suffer any adverse effects of contaminants, and included several lakes within the Kawartha Lakes system to provide comparative data on what was assumed to be an uncontaminated inland breeding population (Ewins et al. 1995; Martin et al. 2003). A colony of Ospreys breeding at high density in Sturgeon Lake was unexpectedly found to be more highly contaminated with PCBs than birds in other areas and monitoring there continued until 2001 (Martin et al. 2003), providing 11 seasons of data on reproduction and nest success relative to various nest substrates.

Nests in the northwestern Kawartha Lakes, including Sturgeon Lake, were primarily located either on artificial nesting platforms or on large flooded stumps which protruded less than $1 \mathrm{~m}$ above the surface of the water. A minority of nests was located in trees or on utility poles. Artificial nest sites of Ospreys in the Great Lakes basin have been shown to have slightly higher productivity and lower collapsing rates compared to natural nest sites (Ewins 1996). Similarly, in Saskatchewan, rates of nest success were greater on artificial structures than natural structures, though productivity was only marginally greater (Houston and Scott 1992). Productivity of Ospreys nesting on artificial sites in Baja Peninsula, Mexico, was higher than those that used natural nest structures (Castellanos and Ortega-Rubio 1995). Thus, we expected that productivity and success would be lower in nests on natural compared to artificial structures. Also, natural nests may be more transitory than artificial nests, so we contrasted longevity of nest use between natural and artificial nests. 


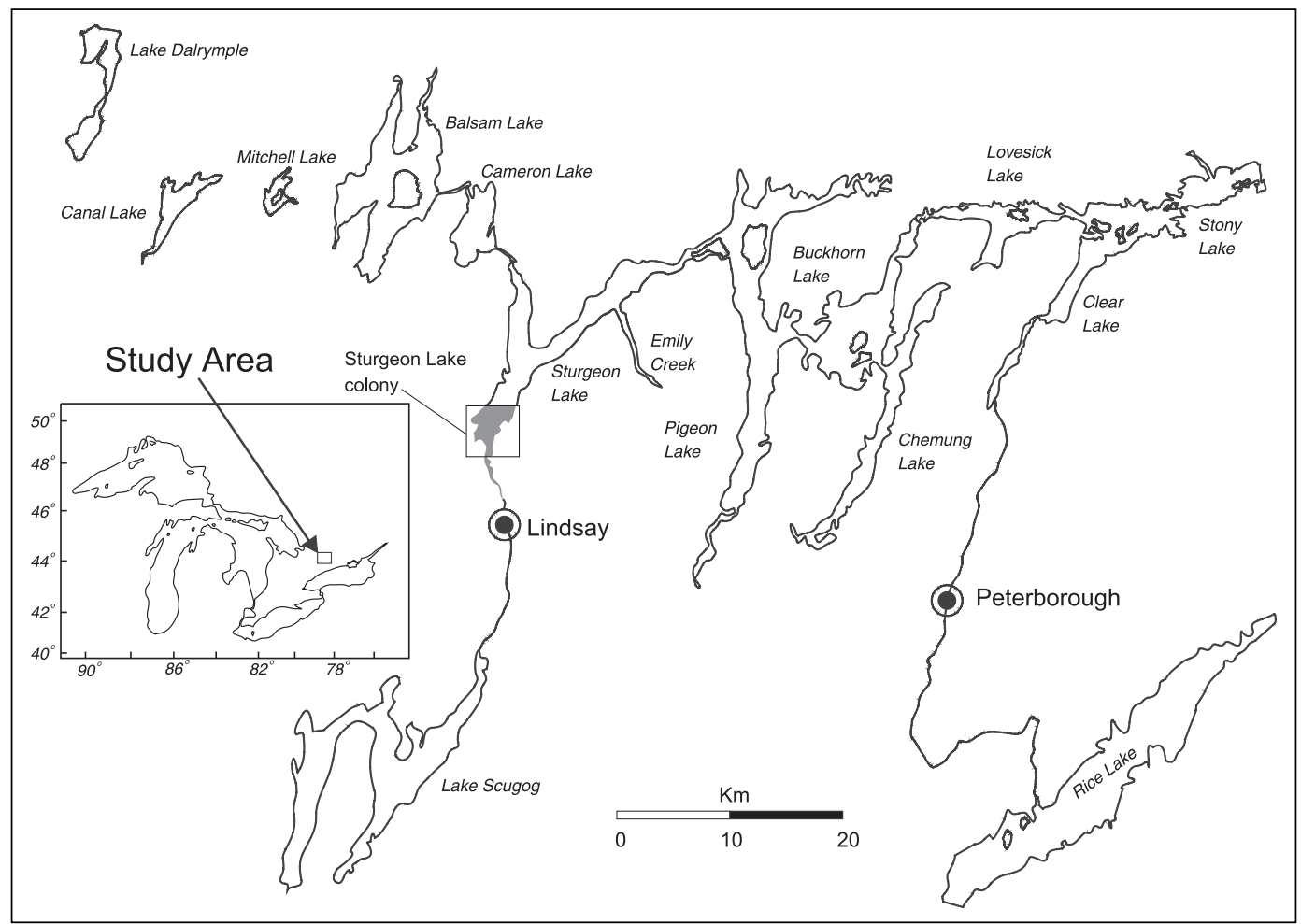

FIGURE 1. Kawartha Lakes study area indicating its position in the Great Lakes basin and the Sturgeon Lake Osprey breeding colony.

\section{Methods and Materials}

The study area was a subset of lakes within the Kawartha Lakes region in southcentral Ontario, a transitional zone bordering the Canadian Shield and the Great Lakes-St. Lawrence Lowlands ecozones. The Kawartha Lakes are a chain of 17 shallow, mainly eutrophic lakes interconnected by a series of rivers and man-made canals. The water levels are controlled in some areas through the use of dams, and the littoral regions of some lakes were flooded as a result of the construction of the Trent-Severn Waterway over the last two centuries

A group of Kawartha Lakes at the northwest end of the chain was surveyed from 1991 to 1996; these included Balsam, Canal, Dalrymple, and Mitchell Lakes and Sturgeon Lake, which included two main nesting areas: Emily Creek and a bay in the south end (Figure 1). The south end of Sturgeon Lake was the site of a fairly dense nesting "colony" of Ospreys, at which as many as 17 occupied nests occurred within a $3.5 \mathrm{~km}$ radius. Monitoring of the Sturgeon Lake colony continued until 2001. Because surveys at Sturgeon Lake continued an additional 5 years (1997 to 2001) beyond those of the other Kawartha Lakes (1991-1996), we tested to determine if productivity was similar before and after 1997 using a two-factor ANOVA, with nest substrate and time period (before 1997 and after 1997) as factors. There were no differences in productivity in relation to either factor or their interaction $(p>0.05)$, so further analyses included data from Sturgeon Lake for all years.

Aside from three nests in dead trees, natural nests all consisted of stumps of trees that had been felled prior to the flooding of land surrounding the original lake basin. One stump nest was later modified to include a box to improve stability, but was nevertheless considered to be a natural nest. The remaining nests were artificial and consisted of utility poles (including one unused television antenna), platforms raised on quadrupod support poles, or duckblinds. Nests were checked twice a year by boat. The first visit was in late May during incubation to count clutch size and determine occupancy. Nests on elevated man-made structures were accessed using an aluminum extension ladder. The second visit was in late June or early July to determine productivity and band chicks. Nests were classified as successful if at least one chick survived to 5 weeks old. Productivity was calculated as mean number of chicks fledged per occupied nest. Productivity and longevity of nests were compared among nest substrates using analysis of variance (ANOVA). 
Frequency tables were used to compare productivity and occupancy rates, both among years and among nest substrates. Pearson $\chi^{2}$ was used to test for differences in frequency. Survival analysis was used to determine if the longevity of nests, defined as the number of years that a nest was occupied, differed among nest substrates. For the survival analysis, the first year that a nest was occupied was treated as year 0 . The KaplanMeier method (Kaplan and Meier 1958) was used to estimate the survival function, and Gehan's generalized Wilcoxon test and Cox's F test were use to contrast survival times among nest types. Statistica 5.5 was used for statistical analyses (StatSoft Incorporated 2000). Statistical significance was inferred at the $\mathrm{P}<0.05$ level.

\section{Results}

During 11 years of monitoring a northwest portion of the Kawartha Lakes region, 260 individual Osprey nesting attempts were made (Table 1). Of these, $43 \%$ were on natural substrates and $57 \%$ were on artificial structures. Of the natural substrates, overwater flooded stumps accounted for the majority, and were used in $37 \%$ of all nests; in contrast, trees provided substrate for only $6 \%$ of all nests (Table 1). The most commonly used artificial structures were the quadrupod nesting platforms (33\% of all nests), followed by utility poles (20\%) and duck blinds (4\%).

There were no differences in productivity among the 5 nest substrates overall (Tree, Stump, Platform, Utility Pole, Duckblind: $\mathrm{P}=0.09$ ). Nevertheless, differences were found when nest substrates were compared within artificial and natural categories. Productivity was higher in Stump nests compared to Tree nests $(\mathrm{P}=0.05)$; however, there were no differences among artificial nest substrates $(\mathrm{P}=0.51)$. Substrates were then pooled into three groups: Stump nests, Tree nests, and Artificial nests. Productivity varied among these three nest substrates $(P=0.04$, Figure 2$)$, and was higher in Stump nests than either Artificial or Tree nests, having 1.48, 1.16 and 0.73 fledged chicks per occupied nest, respectively.

To test effects of nest height on productivity and nest success, we grouped nests according to height:

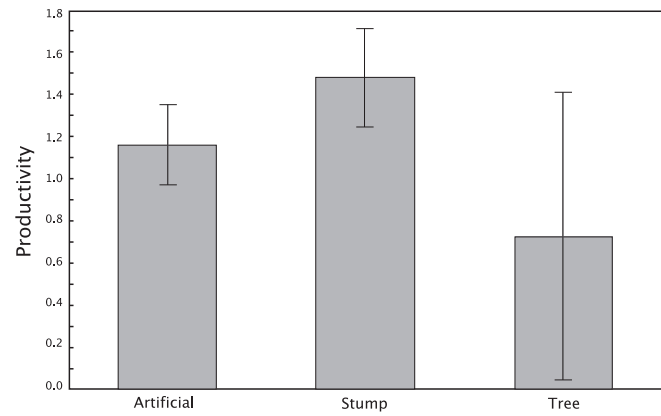

FIGURE 2. Productivity (number of chicks per active nest) of Artificial, Stump and Tree nests of Ospreys in the Kawartha Lakes region, 1991-2001.

those situated greater than $2 \mathrm{~m}$ above water level were High nests (Platform, Tree, and Utility pole nests), and those less than $2 \mathrm{~m}$ above water level as Low nests (Stump and Duck blind nests). As productivity differed among nest substrates independent of height (see above), we used a nested ANOVA, with nest height as a main effect, and nest substrate (Artificial, Stump, and Tree) as the nested factor. There were no differences in productivity between either nest height $(\mathrm{P}=0.50)$ or substrate $(\mathrm{P}=0.08)$ in this analysis.

There was no significant difference in nest success between Platform (58.6\% successful) and Stump nests $\left(68.5 \%\right.$ successful; $\left.\chi_{[2]}^{2}=4.39, \mathrm{P}=0.11\right)$. The proportion of successful and unsuccessful nests varied among years $\left(\chi_{[10]}^{2}=20.15, P=0.03\right)$. The proportion of successful nests varied among years from $40.6 \%$ in 1995 (all lakes, 32 nests) to $91.7 \%$ in 2001 (Sturgeon Lake only, 12 nests).

Survival analysis was used to determine if longevity of nests varied among nest substrates. Because tests associated with survival analysis do not perform well at small sample sizes (StatSoft 2000), we excluded or pooled nest substrates with few observations. Thus, we compared Stump nests to Artificial nests (Utility pole and Platform). We were unable to get a good fit from several theoretical distributions. Annual survival of nests did not appear to vary between nest substrates

TABLE 1. Numbers of occupied unique nests and nest-years for Ospreys from 1991 to 2001 in the Kawartha Lakes. Nest-years was calculated by summing the numbers of years that nests of each substrate were occupied from 1991-2001.

\begin{tabular}{lccc}
\hline \hline Substrate & $\begin{array}{c}\text { Number of } \\
\text { individual nests }\end{array}$ & Number & $\begin{array}{c}\text { Nest-years (1991-2001) } \\
\text { Percent of total }\end{array}$ \\
\hline Artificial & & & 4.2 \\
$\quad$ Duck blind & 5 & 11 & 20.0 \\
$\quad$ Utility pole & 13 & 52 & 32.7 \\
$\quad$ Platform & 19 & 85 & 56.9 \\
$\quad$ Total & 37 & 148 & 36.9 \\
Natural & & & 6.2 \\
$\quad$ Stump & 27 & 96 & 43.1 \\
$\quad$ Tree & 4 & 16 & \\
Total & 31 & 112 & \\
\hline \hline
\end{tabular}



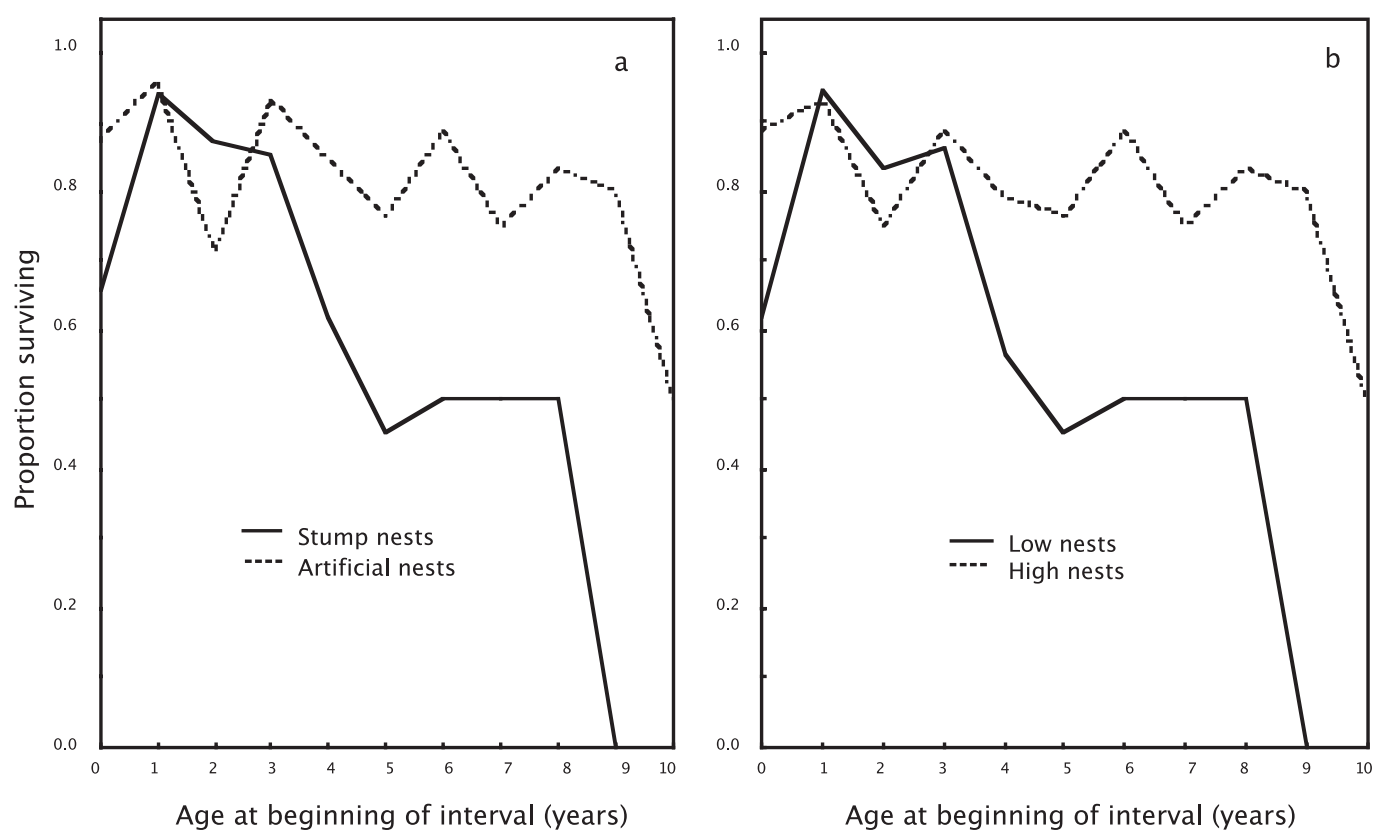

FIGURE 3. Proportion of nests surviving any given year in a) Stump and Artificial nests and b) High and Low nests.

during the first three years of their use (Gehan's Wilcoxon, $P=0.23$ ), whereas after this age, Stump nests tended to have reduced survivorship compared to Artificial nests (Cox's F-test, $\mathrm{F}_{[44,44]}=1.70, \mathrm{P}=0.042$; Figure 3a). Cox's F-test (also known as log-rank) and Gehan's Wilcoxon test emphasize the weight of later vs. earlier censored data, respectively (Fleming et al. 1987). Both Stump and Artificial nests surviving for 6 years appeared to have relatively high survivorship after that point, although the sample size was small for these older nests.

The comparison of longevity of High versus Low nests indicated that High nests had a greater longevity (Gehan's Wilcoxon Test, $\mathrm{P}=0.02$ ). The survivorship of High nests was largely independent of age, whereas Low nests, which were primarily Stump nests, tended to have reduced survivorship after three to five years (Figure 3b). Overall, High nests had greater survivorship than Low nests for all age classes.

\section{Discussion}

Ospreys breeding in the Kawartha Lakes region of south-central Ontario were found to nest successfully on low overwater flooded stumps. We found that, where stumps constituted the primary natural nest substrate, natural nests were more productive than nests built on artificial substrates. This contrasts with the findings of most other comparisons of natural and man-made Osprey nesting substrates. Ewins et al. (1995) found that natural nests, typically trees, were more likely to collapse and had lower productivity than artificial nest structures. Similarly, Westall (1983) found substantially higher productivity on artificial structures (1.47 chicks per occupied nest) compared to natural nests (0.69) on Sanibel Island, Florida. Postupalsky (1977) also reported that nests on artificial substrates, typically man-made nesting platforms or utility poles, had higher productivity than those on natural substrates. Witt (1996), however, found no differences in productivity from nests on man-made platforms versus trees in an Oregon population in which artificial nests comprised $35 \%$ of total active nests. In many studies in the literature however, natural nesting substrates constituted primarily trees, whereas in the current study most natural nests were constructed on low flooded stumps. Stump nests in fact were almost twice as productive as tree nests in the current study, producing a mean of 0.75 chicks per occupied nest more, annually.

Despite the greater productivity of low stump nests, we found that their longevity was not as great as that of platform or utility pole nests. Survivorship of elevated nests appeared to be more independent of age compared to low nests, largely because of the permanency of the structure - utility poles and quadrupod platforms. Low nests consisted primarily of stumps, and occasionally abandoned duck blinds, frequently in disrepair. Thus, elevated nests tended to be available every year, whereas the presence of stump nests was dependent upon sufficiently low water levels to prevent flooding or their destruction by ice action over the winter. We predict that the number of stumps available at Sturgeon and other flooded lakes within 
the Kawartha Lake system will decline over the years as they degrade since further flooding of forested land is not expected. At that point Ospreys may switch to tree nesting or greater use of man-made platforms or utility poles.

That Kawartha Lakes Ospreys nesting on flooded overwater stumps were successful and productive is somewhat surprising, as Ospreys frequently nest on tall structures, presumably in part to avoid depredation. However, natural nests - mostly trees - are typically on shore, whereas the stump nests in our study were surrounded by water, far (usually $>100 \mathrm{~m}$ ) from shore. Great horned owls (Bubo virginianus) appeared to be an important predator of Ospreys in our study area; four nests were found with chicks depredated that were suspected to have been depredated by owls. Thus high nests may be equally or even more vulnerable than low nests to avian predators. Owl hunting patterns may emphasize forested and edge habitat, rather than over open water where the stump nests are located. Another potentially important Osprey nest predator, raccoons (Procyon lotor), also present a greater risk to nearshore nests, and seem reluctant to swim far to access remote overwater nests (Poole 1989). Spring storms causing extreme wave action, waves from motorboats, and sudden alterations in water levels through manipulating of dams, were occasionally suspected of flooding these low nests, resulting in their complete destruction, removal of eggs or chicks, or abandonment (de Solla et al. 2003). Disturbance of nests by humans is another potential cause of nest abandonment or failure; nests located on overwater stumps are much more vulnerable to this impact than those high in trees. The Kawartha Lakes are popular recreational lakes, yet nests in open channels most accessible to humans appeared to suffer no greater failure than those in shallower areas with difficult boat access. The greater stability and possible lower risks of depredation conferred by overwater stump nests over tree nests appeared to account for their success and greater productivity in the current study. Certainly Ospreys in other locations have a propensity to nest in other low overwater sites, with channel navigational markers being a notable example (Poole 1989).

Many long-term programs have been implemented to monitor Osprey populations and improve recruitment, largely through the construction of artificial nesting sites (Barker 1988; Ewins 1996; Witt 1996). Most man-made nest structures consist of platforms erected upon a single pole on land, or upon a tripod or quadrupod in shallow water (Ewins 1994). The high proportion of stump nests at Sturgeon Lake was due to deliberate flooding caused by damming during the construction of the Trent-Severn waterway a century ago. Based upon the results of this study, artificial stump-like structures may also be suitable for Osprey nests, as long as they are built higher than the maximum water level during floods or annual fluctuations and are sufficiently far from shore. Artificial stump nests have the potential advantages of lower cost, lower maintenance, and fewer safety issues than taller structures, and also allow for easier access by researchers to assess nest status and productivity of nests.

\section{Acknowledgments}

Funding for much of this work was supplied by The Ontario Ministry of Natural Resources and Environment Canada's Great Lakes Action Plan. M. Bacro, L. Benner and G. Barrett provided assistance in the field. We are grateful for the Kawartha Lakes Friends of the Osprey Society for logistical support and for maintaining the artificial Osprey nest platforms. We also thank the Otonabee Region Conservation Authority, the former Ontario Hydro and the present Ontario Power Generation for their cooperation.

\section{Documents Cited (marked $*$ in text)}

Barker, M.E. 1988. Osprey nesting survey, Lindsay District. Ontario Ministry of Natural Resources Report. 22 pages.

Ewins, P. J. 1994. Artificial nest structures for Ospreys: a construction manual. Great Lakes Cleanup Fund, Environment Canada, Canadian Wildlife Service, Toronto, Canada. 41 pages.

\section{Literature Cited}

Castellanos, A., and A. Ortega-Rubio. 1995. Artificial nesting sites and Ospreys at Ojo de Liebre and Guerrero Negro Lagoons, Baja California Sur, Mexico. Journal of Field Ornithology 66: 117-127.

de Solla, S. R., P. A. Martin, P. J. Ewins, and M. Barker. 2003. Productivity and population trends of Ospreys in the Kawartha Lakes Region, Ontario, 1991-2002. Journal of Raptor Research 37: 306-313.

Ewins, P. J. 1996. The use of artificial nest sites by an increasing population of Ospreys in the Canadian Great Lakes Basin. Pages 109-123 in Raptors in human landscapes. Edited by D. Bird, D. E. Varland and J. J. Negro, Academic Press, London.

Ewins, P. J., S. Postupalsky, T. Weise, and E. M. Addison. 1995. Changes in the status, distribution and biology of Ospreys (Pandion haliaetus) breeding on Lake Huron. Pages 273-290 in The Lake Huron Ecosystem: ecology, Fisheries and Management. Edited by M. Munawar, T. Edsall and J. Leach, SPD Academic Publishing, Amsterdam, The Netherlands.

Fleming, T. R, D. P. Harrington, and M. O'Sullivan. 1987. Supremum versions of the log-rank and generalized Wilcoxon statistics. Journal of the American Statistical Association 82: 312-320.

Houston, C. S., and F. Scott. 1992. The effect of man-made platforms on osprey reproduction at Loon Lake, Saskatchewan. Journal of Raptor Research 26: 152-158.

Kaplan, E. L., and P. Meier. 1958. Nonparametric estimation from incomplete observations. Journal of the American Statistical Association 53: 457-481.

Martin, P. A., S. R. de Solla, and P. J. Ewins. 2003. Chlorinated hydrocarbon contamination in Osprey eggs and nestlings from the Canadian Great Lakes Basin, 1991-1995. Ecotoxicology 12: 209-224.

Poole, A. F. 1989. Ospreys: a natural and unnatural history. Cambridge University Press, Cambridge, United Kingdom. 
Postupalsky, S. 1977. Artificial nesting platforms for Ospreys and bald eagles. Pages 35-45 in Endangered birds: management techniques for preserving endangered species. Edited by S.A. Temple, University Wisconsin Press, Madison, Wisconsin.

StatSoft, Incorporated. 2000. STATISTICA for Windows [Computer program manual]. Tulsa, Oklahoma.
Westall, M. A. 1983. An Osprey population aided by nest structures on Sanibel Island, Florida. Pages 287-291 in Biology and management of bald eagles and Ospreys. Edited by D. M. Bird, Harpell Press, Ste. Anne de Bellevue, Quebec, Canada.

Witt, J. W. 1996. Long-term population monitoring of Osprey along the Umpqua River in Western Oregon. Journal of Raptor Research 30: 62-69

Received 19 November 2003

Accepted 3 February 2005 